\title{
RANDOMIZED CLINICAL TRIAL IN CHIKUNGUNYA ARTHRITIS CASES
}

Mansoor Ahmed, N. Shantharam, Y. J. Visweswara Reddy.

1. Associate Professor, Department of Community Medicine.MMCRI, Mysore.

2. Formerly Professor \& Head, Department of Community Medicine. PESIMSR, Kuppam.

3. Professor, Department of General Medicine, PESIMSR,Kuppam.

\section{CORRESPONDING AUTHOR}

Dr. Mansoor Ahmed

Associate Professor,

Dept of Community Medicine, MMCRI, Mysore.

E-mail: docmansoor2000@yahoo.com,

Ph: 00919945939275

ABSTRACT: Chikungunya virus is no stranger to the Indian sub-continent. Since its first isolation in Calcutta ${ }^{[1]}$ in 1963, there have been several reports of chikungunya virus infection in different parts of India[2], [3], [4]. The last outbreak of chikungunya virus infection occurred in India in 1971. Subsequently there has been no active or passive surveillance carried out in the country and therefore, it 'seemed' that the virus had 'disappeared' from the subcontinent[5] However, recent reports of large scale outbreaks of fever caused by chikungunya virus infection in several parts of Southern India have confirmed the re-emergence of this virus. It has been estimated that over 1,80,000 cases have occurred in India since December 2005 [6] Andhra Pradesh (AP) was the first state to report this disease in December 2005, and one of the worst affected (over 80,000 suspected cases) . Over $12 \%$ of patients who contract chikungunya virus infection develop chronic joint symptoms ${ }^{[7]}$. OBJECTIVE: To test the efficacy of chloroquine in reducing the pain of chikungunya induced arthritis as compared to paracetamol. METHODOLOGY: A Randomized Clinical Trial was carried out in a community attached to urban health centre of PESIMSR, Kuppam during August 2006. Among the 132 cases of arthritis, 86 persons were selected based on their availability and consent to participate. They were divided into two randomly assigned groups namely Category-1(Chloroquine group) and Category-2 ( Paracetamol group). Chloroquine tablet -155 mg and Paracetamol tablet - $500 \mathrm{mg}$ were administered as a single dose to the two groups respectively. The groups were followed up for 8 days and the results were analyzed. STATISTICAL ANALYSIS: Analysis was carried out by using S.P.S.S. package. Asymptoic test statistic and $\mathrm{X}^{2} \mathrm{MH}$ (Chi square test) were used to evaluate the effect of the drugs. RESULTS OF THE STUDY: The decrease of pain in chikungunya arthritis cases was significant in the mild and moderate pain categories with 'p' values of 0.0117 and 0.0129 respectively.

Asymptoic test statistic was 1.70 for chloroquine group and $\chi^{2} \mathrm{MH}$ was 2.76 (' $\mathrm{P}$ ' value between 0.05 to 0.1 ).OR= 48.59.Incidence Risk Ratio for chloroquine was 1.52 with $\mathrm{CI} ; 1.14$ 1.90.The efficacy of chloroquine in reducing pain in arthritis was $51.83 \%$ ( effect size).The logistic equivalents of odds for chloroquine and paracetamol group were 0.41 and 0.02 respectively in logistic regression analysis. CONCLUSION: Choloroquine is more efficient in reducing the pain of chikungunya arthritis as compared to paracetamol in both sexes and in all age groups.

KEY WORDS: Chikungunya, Arthritis, Clinical Trial, Chloroquine.

INTRODUCTION: Chikungunya virus is no stranger to the Indian sub-continent. Since its first isolation in Calcutta[1] in 1963, there have been several reports of chikungunya virus infection in 
different parts of India[2], [3], [4]. The last outbreak of chikungunya virus infection occurred in India in 1971. Subsequently there has been no active or passive surveillance carried out in the country and therefore, it 'seemed' that the virus had 'disappeared' from the subcontinent[5] However, recent reports of large scale outbreaks of fever caused by chikungunya virus infection in several parts of Southern India have confirmed the re-emergence of this virus. It has been estimated that over 1,80,000 cases have occurred in India since December 2005 [6] Andhra Pradesh (AP) was the first state to report this disease in December 2005, and one of the worst affected (over 80,000 suspected cases) . Over $12 \%$ of patients who contract chikungunya virus infection develop chronic joint symptoms [7].

Chikungunya arthritis is a crippling and chronic sequel of chikungunya fever causing a lot of pain and distress to the patients.

Chloroquine is a disease modifying, non steroidal drug known also to have antirheumatic effect[8]. The therapeutic dose of chloroquine is $150 \mathrm{mg}$. It has a half-life of 4 days and the therapeutic effect is said to last upto 16 days after cessation of treatment. It is a safe drug in this dose as it has been extensively used in malaria treatment.

Only one previous study of using chloroquine in patients with chikungunya arthritis has been documented earlier [9]

The present study was carried out to test the efficacy of chloroquine in reducing the pain of chikungunya arthritis patients as compared to paracetamol.

MATERIALS AND METHODS: A randomized double blind clinical trial was conducted in a community attached to the urban health centre of PESIMSR, Kuppam . The study was conducted in the post epidemic period of chikungunya during August 2006.

STUDY POPULATION: The study population constituted the patients having post chikungunya arthritis. A door to door survey was done by health workers to check for these cases in the entire community. The investigators screened all patients and selected 86 arthritis patients with the following criteria.

INCLUSION CRITERIA: Only those subjects with post chikungunya arthritis.

\section{EXCLUSION CRITERIA:}

1. Those subjects not giving their consent to participate in the study.

2. Known cases of rheumatoid arthritis /osteo arthritis /other degenerative diseases.

RANDOMIZATION AND ALLOCATION CONCEALMENT: The drugs chloroquine and paracetamol were packed in brown envelopes as a single dosage form separately in 86 sealed covers. These covers were having 43 dosage forms of chloroquine and paracetamol each. The 86 packs were given numbers from a random number table. Thus 86 randomized packs were prepared. The contents of the covers were not noted on the cover. These covers were taken to the field and were administered to the patients recruited on a sequential basis. Thus allocation concealment was done. Thus two groups of patients, one receiving the white capsule and the other receiving the red capsule were formed.

All patients were followed up by investigators for a period of 8 days after initial clinical assessment.

Journal of Evolution of Medical and Dental Sciences/Volume1/Issue5/November-2012Page-842 


\section{MATERIALS:}

1) A pretested proforma and follow up record.

2) Visual analogue scale to assess the pain reduction.

3) Drugs : Chloroquine $150 \mathrm{mg}$ base filled in a white gelatin capsule and paracetamol 500 mg filled in a red gelatin capsule of the same type.

DOSAGE ADMINISTRATION: After formation of the groups the white capsule group was given chloroquine and the red capsule group was given paracetamol as a daily single dose. Directly observed, supervised treatment was administered.

QUALITY CONTROL: The investigators had several meetings along with the patients and had a common clinical assessment agreement. Thus inter and intra observer variation was minimized.

The random number allocation for packets was done by the statistician who was not participating in analysis. The key for the packets were with the same statistician.

EVALUATION OF PATIENTS: Only one end point, viz., the reduction of pain was assessed by the investigators using visual analogue scale. The monitoring of patients was done by the investigators who initially assessed them.

Out of 132 cases of arthritis, 86 persons were selected based on their availability and consent to participate. This study group was divided into 2 randomly assigned groups namely Category - 1(Chloroquine group) and Category - 2 (Paracetamol group). Informed consent was taken from all the respondents.

The trial was double blind and the first author had the key. The two groups were similar in all aspects. Chloroquine tab - $155 \mathrm{mg}$ single dose was given to the chloroquine group and Paracetamol tab - $500 \mathrm{mg}$ single dose was given to the paracetamol group.

The pain was classified into severe, moderate and mild as per the expression of patients. The relief of pain was graded into reduction by $25 \%, 50 \%, 75 \%$ and above $75 \%$ as expressed by patients. The patients were followed up for 8 days and the results were recorded.

STATISTICAL ANALYSIS: Statistical analysis was done by using the SPSS package. Analysis was done on risk approach basis. Asymptoic test and $\chi^{2}$ (chi square test) with $\mathrm{MH}$ treatment were used to evaluate the effect of the drugs.

RESULTS: Response to treatment was favourable for chloroquine irrespective of the degree of pain. The decrease of pain in chikungunya arthritis cases was significant in mild and moderate categories with 'p' values of 0.0117 and 0.0129 respectively.

Increasing age had no effect on the relief of the pain (' $r$ ' was not significant). There was no difference in the relief of pain in both sexes with increasing age.

It was observed that the Incidence Risk Ratio for chloroquine was 1.52 with CI ; 1.14 1.90 .

The efficacy of chloroquine in reducing pain in arthritis was $51.83 \%$ (effect size).

The decrease of pain in the chloroquine group was $95.34 \%$ and in the paracetamol group it was $62.79 \%$ giving a risk difference of 32.55 . 
In the choloroquine group, the median age was 40.2 and the inter-quartile range was 31.7 to 45.5

In the paracetamol group, the median age was 45.4 and the inter-quartile range was 35.4 to 56.5. No significant difference was seen between the two groups.

The proportion of mild, moderate, and severe pain categories was almost similar in both the groups. The sex ratio of both the groups was also similar.

The logistic equivalents of odds for chloroquine and paracetamol groups were 0.41 and 0.02 respectively.

Results of standardized analysis : $\mathrm{OR}=48.59$

$\chi^{2}{ }_{\mathrm{MH}}=2.76 ;$ Asymptoic test statistic $=1.70$.

'P' value lies between 0.05 to 0.1 .

DISCUSSION: In this study it has been observed that the drug chloroquine is quite efficient in reducing the pain of chikungunya arthritis. Though paracetamol also helps in reducing the pain it is less effective than chloroquine in this regard. These findings are in conformity with an earlier study ${ }^{[8]}$ where it was observed that the symptoms of chikungunya arthritis improved significantly following chloroquine treatment.Very few studies have been reported on the use of chloroquine in chikungunya arthritis cases and these results justify further controlled blind trials of chloroquine in their treatment .

CONCLUSION: Choloroquine is more efficient in reducing the pain of chikungunya arthritis as compared to paracetamol in both sexes and all age groups.

LIMITATIONS: The number of severe cases included in the trial was less. Therefore, the adequacy of chloroquine in reducing the pain in these circumstances cannot be assumed. A larger number of severe cases need to be included in future trials. The dose of chloroquine to be given in severe cases also requires further study.

\section{REFERENCES:}

1. Shah KV, Gibbs CJ Jr, Banerjee G. Virological investigation of the epidemic of haemorrhagic fever in Calcutta: isolation of three strains of Chikungunya virus. Indian J Med Res 1964; 52 :676-83.

2. Jadhav M, Namboodripad M, Carman RH, Carey DE, Myers RM. Chikungunya disease in infants and children in Vellore: a report of clinical and haematological features of virologically proved cases. Indian J Med Res 1965; 53:764-76.

3. Dandawate CN, Thiruvengadam KV, Kalyanasundaram V, Rajagopal J, Rao TR. Serological survey in Madras city with special reference to chikungunya. Indian J Med Res 1965; 53 :707-14.

4. Thiruvengadam KV, Kalyanasundaram V, Rajgopal J. Clinical and pathological studies on chikungunya fever in Madras city. Indian J Med Res 1965; 53 :729-44.

5. Pavri K. Disappearance of Chikungunya virus from India and South East Asia. Trans R Soc Trop Med Hyg 1986;80:491.

6. Enserink M. "Massive outbreak draws fresh attention to little-known virus". Science 2006; 311 :1085.

7. CDC. Chikungunya Fever in India. Travelers' Health Outbreak Notice April 21, 
2006.http://www.cdc.gov/travel

8. Brighton SW, Simson IW. A destructive arthropathy following chikungunya virus arthritis: a possible association. Clin Rheumatol 1984; 3(2) : 253 - 8

9 Brighton SW. Chloroquine phosphate treatment of chronic chikungunya arthritis: an open pilot study. S Afr Med J 1984; 66(6):217 - 8.

Table - 1: Response to Chloroquine vs Paracetamol :

\begin{tabular}{|c|c|c|c|c|}
\hline \multirow{2}{*}{ Arthritis } & \multicolumn{2}{|c|}{ Chloroquine group } & \multicolumn{2}{c|}{ Paracetamol group } \\
\cline { 2 - 5 } & Cured & Not cured & Cured & Not cured \\
\hline Mild & 27 & 02 & 20 & 10 \\
\hline Moderate & 12 & 00 & 05 & 06 \\
\hline Severe & 02 & 00 & 02 & 00 \\
\hline TOTAL & $\mathbf{4 1}$ & $\mathbf{0 2}$ & $\mathbf{2 7}$ & $\mathbf{1 6}$ \\
\hline
\end{tabular}

Table - 2: The response to Chloroquine in reduction of pain vs Paracetamol with age and sex.

\begin{tabular}{|c|c|c|}
\hline \multirow{2}{*}{ Age } & Male & Female \\
\cline { 2 - 3 } & Cured & Cured \\
\hline $0-20$ & 2 & 0 \\
\hline $20-30$ & 4 & 1 \\
\hline $30-40$ & 14 & 4 \\
\hline $40-50$ & 12 & 12 \\
\hline $50-60$ & 06 & 03 \\
\hline $60-80$ & 03 & 07 \\
\hline TOTAL & $\mathbf{4 1}$ & $\mathbf{2 7}$ \\
\hline
\end{tabular}

Table - 3: Risk Analysis

\begin{tabular}{|l|l|}
\hline & \multicolumn{1}{|c|}{$\begin{array}{c}\text { Chloroquine Vs } \\
\text { Paracetamol }\end{array}$} \\
\hline Risk difference & 32.55 \\
\hline IRR & 1.52 \\
\hline C.I. with 95\% Confidence limits & $\begin{array}{l}(1.14-1.90) \\
0.2 \text { to } 0.05\end{array}$ \\
\hline Efficacy of chloroquine & 51.83 \\
\hline
\end{tabular}

Journal of Evolution of Medical and Dental Sciences/Volume1/Issue5/November-2012Page-845 
Fig-1: Comparison of age among Chloroquine and Paracetamol groups:

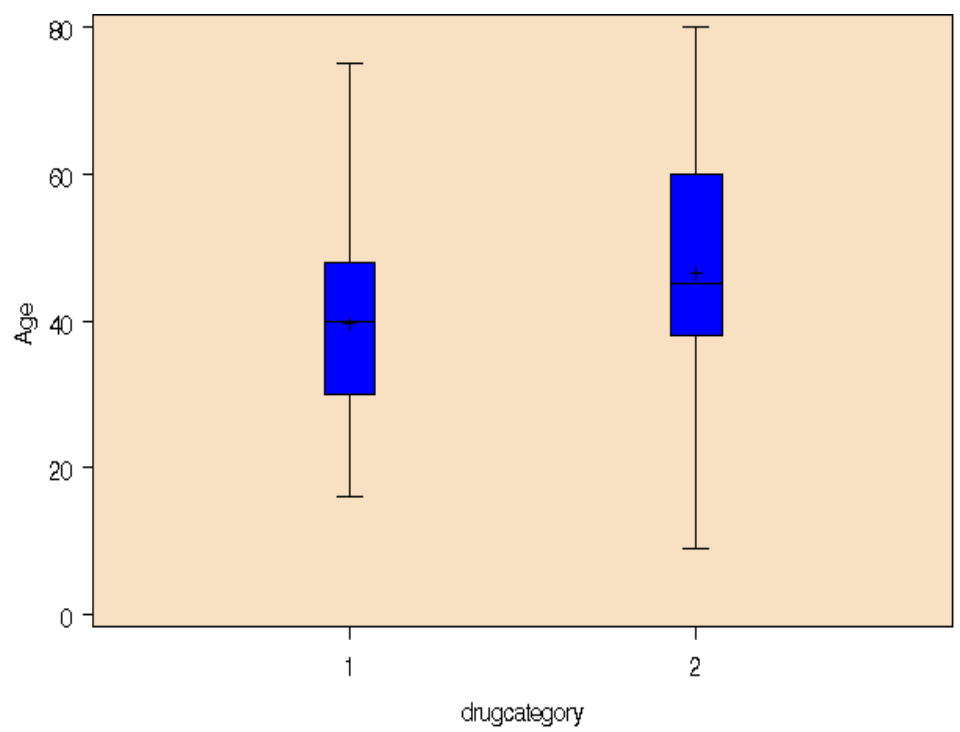

Fig - 2 : Category-wise distribution of cases

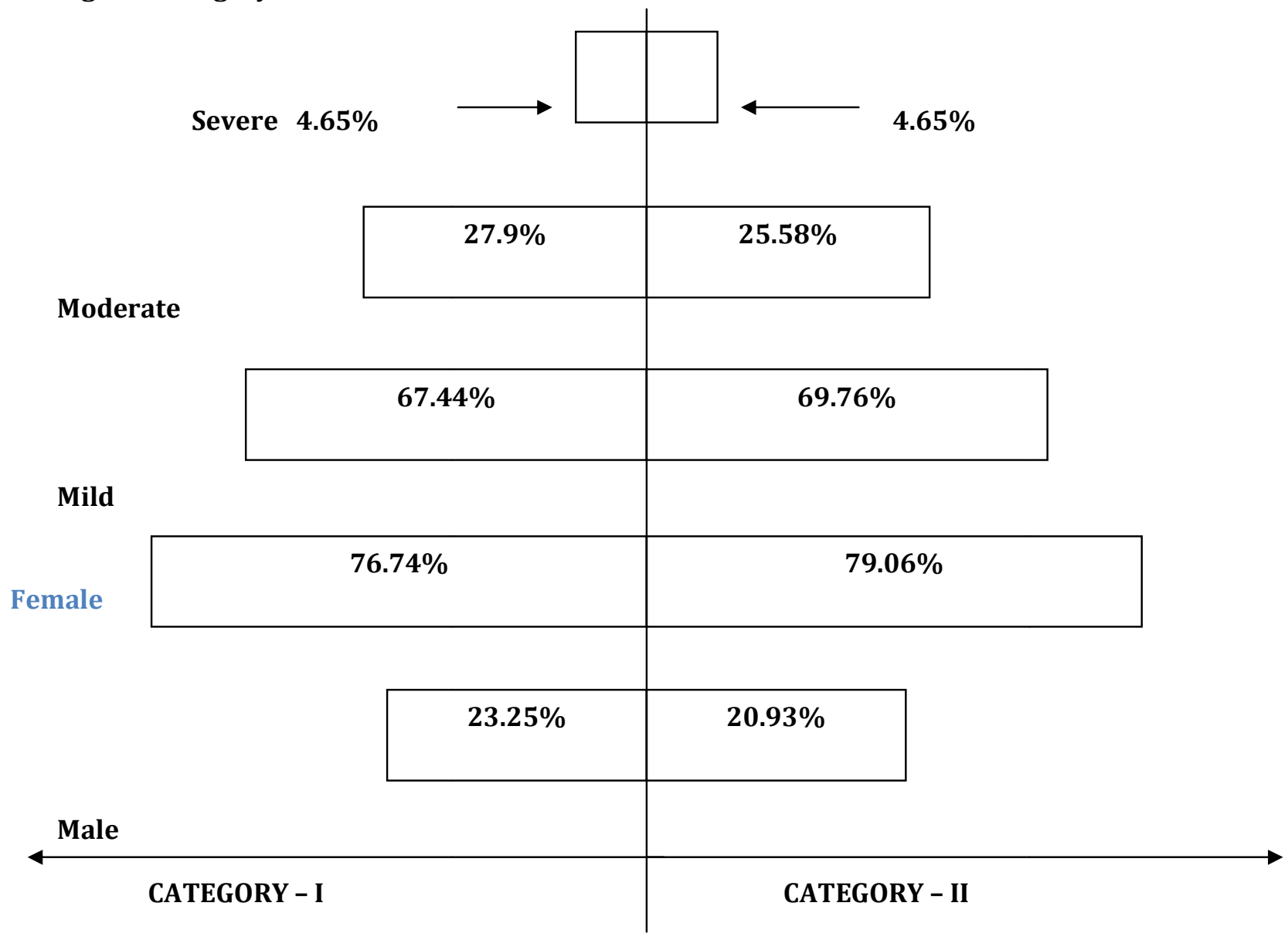

Journal of Evolution of Medical and Dental Sciences/Volume1/Issue5/November-2012Page-846 
Fig 3 : Logistic Regression Analysis for Chloroquine Vs Paracetamol

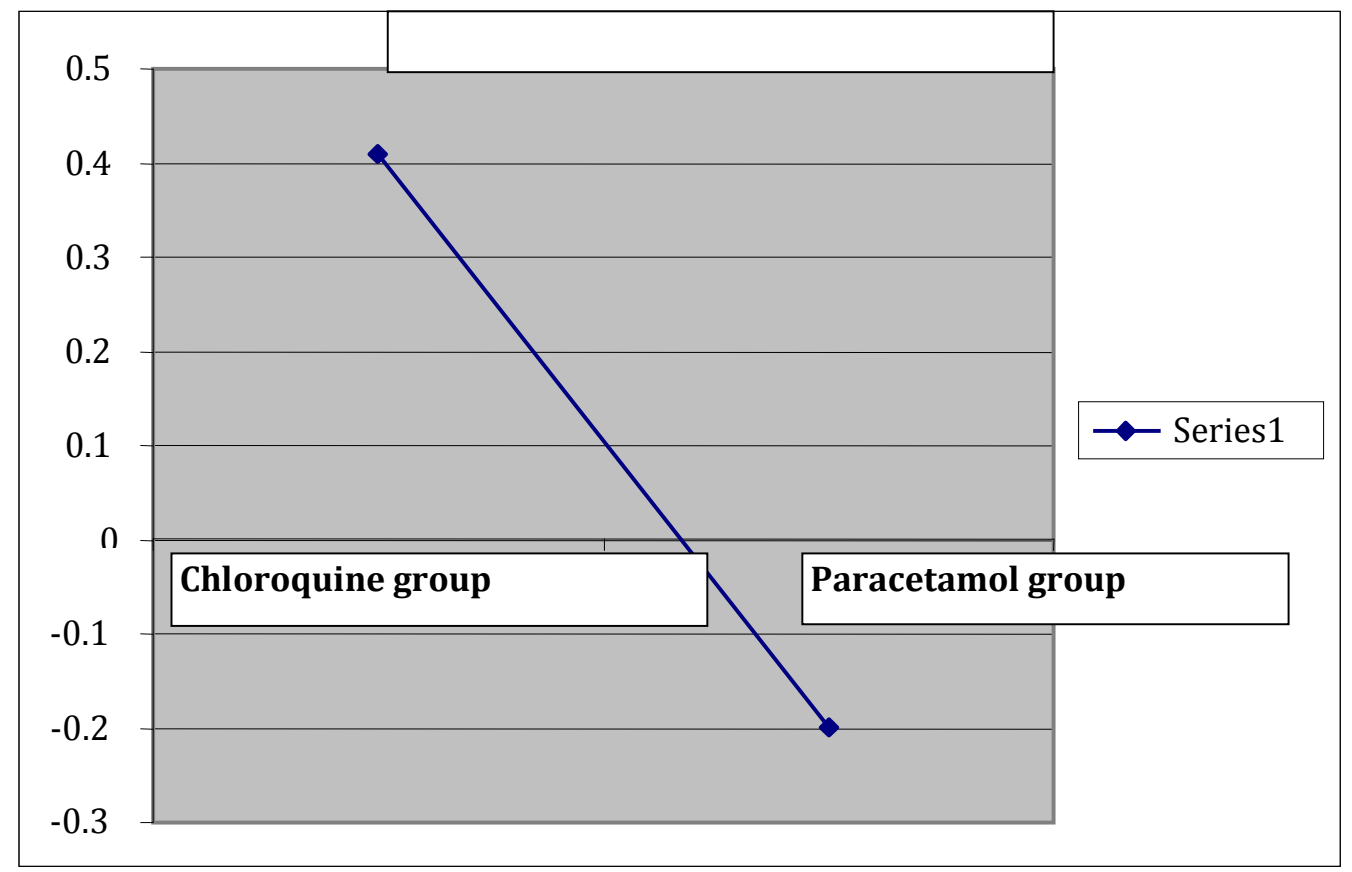

